\title{
DEVELOPMENT OF EMPIRICAL DIETARY INFLAMMATORY PATTERN (EDIP) SCORES WITH DIFFERENT FOOD GROUPS AND BIOMARKERS
}

\author{
EMMA GUYONNET ${ }^{1}$, MILLICENT AMANKWAH ${ }^{2}$, YALEI CHEN ${ }^{3}$, \\ RACHEL MARTINI ${ }^{4}$, MELISSA DAVIS ${ }^{4}$, LISA NEWMAN $^{4}$ \\ 1 University of Toronto, Toronto, Canada. \\ 2 Hartford HealthCare Medical Group, Prospect, CT, USA. \\ 3 Henry Ford Cancer Institute, Detroit, MI, USA. \\ 4 Weill Cornell Medicine, New York, NY, USA.
}

\begin{abstract}
Background: The empirical dietary inflammatory pattern (EDIP) is a hypothesisdriven dietary pattern used to assess the inflammatory potential of diet in the US population. Food-frequency questionnaire responses are used to build regression models comparing this dietary information to circulating inflammatory profiles to help determine which food groups have more or less inflammatory potential on specific individuals. We will eventually use this tool in a cancer patient intervention to modify inflammation and improve chances of survival.
\end{abstract}

Methods: EDIP scores were calculated for 4 models from 24-hour recalls reported by 67 women noncancer controls that had signed an informed consent prior to participation. The Luminex Human Chemokine Multiplex Assay was used to measure 11 chemokines and cytokines. As seen in previous studies, we first derived a model, EDIP-Limited (EDIP-L), by using a reduced rank regression model of all 17 food groups followed by a multivariable regression analysis to identify a dietary pattern that predicts concentrations of two inflammatory biomarkers: IL-6 and TNF-a. We derived a secondary EDIP score using a new model, EDIP-All Inclusive (EDIP-AI), which included the same 17 food groups to predict all 11 circulating biomarkers in our panel. Lastly, we developed two additional EDIP models to test how the biomarker predication may change when we regrouped our food variables from 17 to 14 groupings. EDIP-Limited New (EDIP-LN) used 14 new food groups derived from the same 24-hour recalls, only predicting IL-6 and TNF-a. EDIP-All New (EDIP-AN) used those same 14 food groups with all 11 biomarkers.

Results: In this study, we optimize models for EDIP and report the differences in EDIP scores based on the inflammatory biomarkers and food groups used in analysis. Briefly, the components of EDIP-L were not significant. After including all the biomarkers, the components of EDIP-AI were: "fruit juice" ( $p=0.0009)$, "snacks" ( $p$ $=0.0008)$, "leafy green vegetables" ( $p=0.0074)$, "low-energy beverages" ( $p=0.0098)$, 


\section{Columbia Undergraduate Research Journal}

"red meat" ( $p=0.0038)$, "fruit" $(p=0.0002)$, and "whole wheat grains" $(p=0.0138)$. Similarly, after reorganizing our food items into 14 food groups, the components of EDIP-LN were not significant. However, components of EDIP-AN were: "fruit juice" ( $p=0.0107)$, “snacks" ( $p=0.0116)$, and "fruit" ( $p=0.0026)$.

Conclusions: Findings demonstrate the EDIP scores differ based on the inflammatory biomarkers and food groups used in the analysis on the same noncancer controls. Depending on the methods used, an individual's diet may be considered more pro- or anti-inflammatory. This study provides insight into the inflammatory potential of an individual's diet and the factors that may affect how we calculate this potential. 


\section{Columbia Undergraduate Research Journal}

\section{Introduction}

hemokines are small inflammatory molecules that, in conjunction with their
receptors, recruit lymphocytes to mediate immune and inflammatory
responses (1). The Duffy Antigen Receptor for Chemokines (DARC) is a nonsignaling receptor that binds pro-inflammatory chemokines, regulating homeostatic levels of chemokines in circulation, and subsequently mediates immune response (2). DARC is also an entry point for Plasmodium vivax, a parasite that causes malaria. In Sub-Saharan Africa, where malaria is common, a mutation, known as the Duffy-Null allele, arose, removing DARC expression from red blood cells (RBCs) (3). Since removing DARC from RBCs confers immunity from this malaria pathogen to DuffyNull individuals, the Duffy-Null allele rose to fixation in this population, and many descendants of Sub-Saharan Africans carry this allele (3). The women that carry this allele are often diagnosed with the most aggressive type of breast cancer, triple negative breast cancer (TNBC) (4). Removal of DARC suggests there could be an excess of chemokines in breast tumor microenvironment, increasing risk of metastasis and/or more aggressive tumor histopathological phenotypes, rendering this breast cancer more deadly (5).

Inflammation is a common condition in some types of cancer; for example, women with inflammatory breast cancer are typically associated with worse outcomes compared to women with non-inflammatory breast cancer (6). As a result, the study of genetics and modifiable factors, such as diet and lifestyle, has gained importance over the past few years. In particular, diet has an effect on the whole body of an individual by providing nutrients and other compounds that directly impact inflammatory response and gene expression. Diet can be influenced by environmental factors, such as socioeconomic status and culture, but it also involves an interaction between nutrients and bioactive compounds (7). Here, an empirical approach is developed to determine the dietary patterns that explain the variation in blood inflammatory biomarkers (8).

Recently, the empirical dietary inflammatory pattern (EDIP) score was developed in the United States (US) (9). EDIP is a hypothesis-driven dietary pattern, developed using the reduced rank regression method, that assesses the inflammatory potential of diet in the US population. The reduced rank regression (RRR) determines linear functions of predictors by maximizing the explained variation in the responses (10-12). It uses information on the response variables to derive the dietary patterns, which are the quantity or combination of different foods in one's diet and the frequency with which they are consumed. In this study, blood samples were collected from subpopulations of the Nurses' Health Study (NHS), NHS-II, and Health Professionals Follow-up Study (HPFS) cohorts. With data from two food frequency questionnaires (FFQ), they entered 39 pre-defined food groups in reduced rank regression models followed by stepwise linear regression analyses in the NHS to 


\section{Columbia Undergraduate Research Journal}

identify a dietary pattern predictive of IL-6, CRP, and TNFaR2. The final EDIP was the weighted sum of 18 food groups, which was then evaluated in 2 samples from NHS-II and HPFS. In NHS-II and HPFS, the EDIP significantly predicted concentrations of all biomarkers; therefore the EDIP is useful in assessing the inflammatory potential of whole diets (9). Since chronic inflammation plays an important role in the development of many chronic diseases (13-15), this index tells us which foods could be linked to this inflammation. For example, the Mediterranean diet has been associated with lower concentrations of pro-inflammatory markers, while the Western diet has been associated with higher concentrations of pro-inflammatory markers. Our objective in this study is to derive our own EDIP scores in a noncancer control sample using a variety of inflammatory biomarkers and food items from 24hour recalls. Ultimately, we aim to apply these findings to a sample of women with TNBC to determine the effect dietary patterns have on inflammation in TNBC, especially among Duffy-Null women who typically have higher levels of circulating inflammatory chemokines.

\section{Materials and Methods}

\section{IRB information / Ethics Statement}

All biospecimens and survey responses in this human subjects study were collected at the University of Georgia (Athens, GA) under an institutional review board (IRB) approved protocol (IRB ID: MOD00003730). All research was performed following the IRB guidelines and a filed assurance of the IRB by the U.S. Department of Health and Human Services. All participants signed an informed consent about the study procedures before participating and donating blood and questionnaire responses.

\section{Questionnaire}

At the time of blood sample collection, noncancer control participants ( $\mathrm{n}=$ 67) completed a questionnaire that collected information regarding sociodemographic information, medical history (including specific questions regarding reproductive history), family history, questions regarding tobacco and alcohol use, and a 24-hour diet recall.

\section{Nutrition survey responses and analysis}

In the first part of the analysis, the various food items from the 24-hour diet recall questionnaire responses were organized into the following 17 food groups described in Table 1: Fruit juice, Snacks, Leafy green vegetables, Dark yellow 
vegetables, Caffeine, Low-energy beverages, High-energy beverages, Refined grains, Other vegetables, Processed meat, Red meat, Fruit, Whole wheat grains, Dairy, Sweets and Desserts, Nuts, and Beans. The food items from the same 24-hour diet recall questionnaire responses were reorganized into the following 14 food groups for subsequent analysis, and are described in Table 2: Fruit juice, Snacks, Leafy green vegetables, Dark yellow vegetables, Low-energy beverages, High-energy beverages, Other vegetables, Grains, Meat, Fruit, Dairy, Sweets and Desserts, Nuts, and Beans. Here, Red meat was grouped with Processed meat into the food group Meat, Caffeine was grouped with High-energy beverages, and Whole wheat grains was combined with Refined grains into Grains.

Table 1: Original 17 food groups description.

\begin{tabular}{|c|c|c|c|}
\hline $\begin{array}{c}\text { Group } \\
\quad \#\end{array}$ & Food Groups & Food Items & $\begin{array}{l}\text { Mean } \\
\text { Intakes }\end{array}$ \\
\hline 1 & Fruit juice & $\begin{array}{l}100 \% \text { juice drink like orange juice, apple juice, } \\
\text { or grape juice }\end{array}$ & 0.403 \\
\hline 2 & Snacks & $\begin{array}{l}\text { Potato chips, tortilla chips, Cheetos, corn } \\
\text { chips, or other snack chips }\end{array}$ & 0.627 \\
\hline 3 & $\begin{array}{l}\text { Leafy green } \\
\text { vegetables }\end{array}$ & $\begin{array}{l}\text { Lettuce, any green vegetables like spinach, } \\
\text { green beans, broccoli, other greens }\end{array}$ & 0.716 \\
\hline 4 & $\begin{array}{ll}\text { Dark } & \text { yellow } \\
\text { vegetables } & \end{array}$ & Carrots, squash, or sweet potatoes & 0.522 \\
\hline 5 & Caffeine & $\begin{array}{l}\text { Coffee, tea, iced tea, or coffee drinks like a } \\
\text { Frappuccino }\end{array}$ & 1.433 \\
\hline 6 & $\begin{array}{l}\text { Low-energy } \\
\text { beverages }\end{array}$ & Diet sodas or soft drinks & 0.313 \\
\hline 7 & $\begin{array}{l}\text { High-energy } \\
\text { beverages }\end{array}$ & $\begin{array}{l}\text { Kool-Aid, sports drinks, or other fruit flavored } \\
\text { drinks, regular sodas or soft drinks }\end{array}$ & 0.343 \\
\hline 8 & Refined grains & $\begin{array}{l}\text { White bread, buns, bagels, tortillas, or rolls, } \\
\text { hot/cold cereal, brown rice, farro, macaroni, } \\
\text { spaghetti, or pasta noodles }\end{array}$ & 0.562 \\
\hline 9 & Other vegetables & $\begin{array}{l}\text { Green peppers, tomatoes, zucchini, asparagus, } \\
\text { cabbage, cauliflower, cucumbers, mushrooms, } \\
\text { eggplant, celery, artichokes, potatoes, corn, or } \\
\text { peas }\end{array}$ & 0.619 \\
\hline 10 & Processed meat & $\begin{array}{l}\text { Fried chicken, chicken nuggets, chicken fried } \\
\text { steak, fried pork chops, fried fish, fish sticks }\end{array}$ & 0.239 \\
\hline 11 & Red meat & $\begin{array}{l}\text { Hamburger, hot dogs, chorizo, steak, bacon, } \\
\text { ribs }\end{array}$ & 0.552 \\
\hline 12 & Fruit & $\begin{array}{l}\text { Fruits are all fresh, frozen, canned or dried } \\
\text { fruits }\end{array}$ & 1.239 \\
\hline 13 & Whole Wheat Grains & $\begin{array}{l}\text { Dark bread, buns, bagels, tortillas, or rolls or } \\
\text { corn tortillas }\end{array}$ & 0.463 \\
\hline 14 & Dairy & $\begin{array}{l}\text { Cheese, chocolate or other flavored milk, milk } \\
\text { on cereals, and drinks made with milk, yogurt } \\
\text { or cottage cheese or drink a yogurt drink }\end{array}$ & 0.816 \\
\hline
\end{tabular}




\section{Columbia Undergraduate Research Journal}

\begin{tabular}{|l|l|l|l|}
\hline 15 & Sweets and desserts & $\begin{array}{l}\text { A cold, sweet food like ice cream, frozen } \\
\text { yogurt, an ice cream bar, or a popsicle, any } \\
\text { sweet rolls, donuts, cookies, brownies, pies, or } \\
\text { cakes, chewy, gummy, hard or chocolate candy }\end{array}$ & 0.428 \\
\hline 16 & Nuts & $\begin{array}{l}\text { Peanuts, peanut butter, or other nuts such as } \\
\text { pecans, walnuts, or almonds }\end{array}$ & 0.821 \\
\hline 17 & Beans & $\begin{array}{l}\text { Pinto beans, baked beans, kidney beans, } \\
\text { refried beans, or pork and beans }\end{array}$ & 0.209 \\
\hline
\end{tabular}

Table 2: Revised food groups description.

\begin{tabular}{|c|c|c|c|}
\hline $\begin{array}{c}\text { Group } \\
\#\end{array}$ & Food Groups & Food Items & $\begin{array}{l}\text { Mean } \\
\text { Intakes }\end{array}$ \\
\hline 1 & Fruit juice & $\begin{array}{l}100 \% \text { juice drink like orange juice, apple juice, } \\
\text { or grape juice }\end{array}$ & 0.403 \\
\hline 2 & Snacks & $\begin{array}{l}\text { Potato chips, tortilla chips, Cheetos, corn } \\
\text { chips, or other snack chips }\end{array}$ & 0.627 \\
\hline 3 & $\begin{array}{ll}\text { Leafy } & \text { green } \\
\text { vegetables } & \end{array}$ & $\begin{array}{l}\text { Lettuce, any green vegetables like spinach, } \\
\text { green beans, broccoli, other greens }\end{array}$ & 0.716 \\
\hline 4 & $\begin{array}{ll}\text { Dark } & \text { yellow } \\
\text { vegetables }\end{array}$ & Carrots, squash, or sweet potatoes & 0.522 \\
\hline 5 & $\begin{array}{l}\text { Low-energy } \\
\text { beverages }\end{array}$ & Diet sodas or soft drinks & 0.313 \\
\hline 6 & $\begin{array}{l}\text { High-energy } \\
\text { beverages }\end{array}$ & $\begin{array}{l}\text { Kool-Aid, sports drinks, or other fruit flavored } \\
\text { drinks, regular sodas or soft drinks, coffee, tea, } \\
\text { iced tea, or a Frappuccino }\end{array}$ & 1.776 \\
\hline 7 & Other vegetables & $\begin{array}{l}\text { Green peppers, tomatoes, zucchini, asparagus, } \\
\text { cabbage, cauliflower, cucumbers, mushrooms, } \\
\text { eggplant, celery, artichokes, potatoes, corn, or } \\
\text { peas }\end{array}$ & 0.619 \\
\hline 8 & Grains & $\begin{array}{l}\text { White bread, buns, bagels, tortillas, or rolls, } \\
\text { hot/cold cereal, brown rice, farro, macaroni, } \\
\text { spaghetti, or pasta noodles, Dark bread, buns, } \\
\text { bagels, tortillas, or rolls or corn tortillas }\end{array}$ & 1.025 \\
\hline 9 & Meat & $\begin{array}{l}\text { Fried chicken, chicken nuggets, chicken fried } \\
\text { steak, fried pork chops, fried fish, fish sticks, } \\
\text { hamburger, hot dogs, chorizo, steak, bacon, } \\
\text { ribs }\end{array}$ & 0.791 \\
\hline 10 & Fruit & $\begin{array}{l}\text { Fruits are all fresh, frozen, canned or dried } \\
\text { fruits }\end{array}$ & 1.239 \\
\hline 11 & Dairy & $\begin{array}{l}\text { Cheese, chocolate or other flavored milk, milk } \\
\text { on cereals, and drinks made with milk, yogurt } \\
\text { or cottage cheese or drink a yogurt drink }\end{array}$ & 0.816 \\
\hline 12 & Sweets and desserts & $\begin{array}{l}\text { A cold, sweet food like ice cream, frozen } \\
\text { yogurt, an ice cream bar, or a popsicle, any } \\
\text { sweet rolls, donuts, cookies, brownies, pies, or } \\
\text { cakes, chewy, gummy, hard or chocolate candy }\end{array}$ & 0.428 \\
\hline 13 & Nuts & $\begin{array}{l}\text { Peanuts, peanut butter, or other nuts such as } \\
\text { pecans, walnuts, or almonds }\end{array}$ & 0.821 \\
\hline
\end{tabular}




\begin{tabular}{|l|l|l|l|}
\hline 14 & Beans & $\begin{array}{l}\text { Pinto beans, baked beans, kidney beans, } \\
\text { refried beans, or pork and beans }\end{array}$ & 0.209 \\
\hline
\end{tabular}

\section{Blood specimens and Luminex human chemokine multiplex assay}

Collection, processing and Luminex multiplex assay of the samples analyzed in this study have been previously described (16). Briefly, blood samples were collected at the Clinical and Translational Research Unit at the University of Georgia (CTRU, Athens, GA; $\mathrm{n}=84$ ). The blood samples were processed within 24 hours of collection, and undiluted plasma was collected from centrifugation and used for the Luminex human chemokine assay. The following chemokines, cytokines, and adipokines were assayed: CCL2/MCP-1， CCL19/MIP-3b， CCL21/6Ckine， CXCL8/IL-8, CXCL9/MIG, IL-6, TNF-a, PAI-1, Leptin, Adipsin, Adiponectin. The distributions, means, and standard deviations from the Luminex assay are shown in Figure 1.
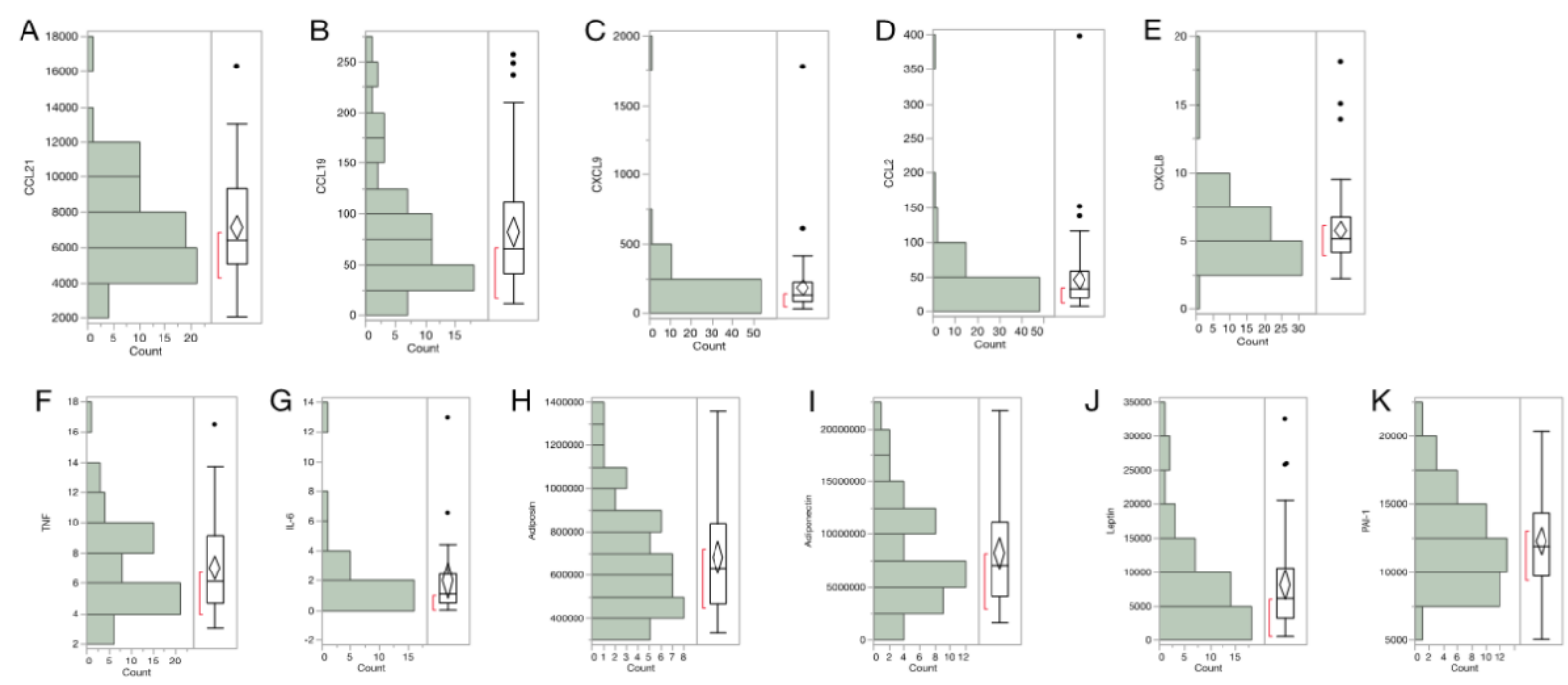

Figure 1: Distribution of chemokines.

(A) Distribution of CCL21 (Mean (SD): 7146.7 (2631.7)), (B) Distribution of CCL19 (83.2 (59.2)), (C) Distribution of CXCL9 (188.8 (223.9)), (D) Distribution of CCL2 (46.6 (52.4)), (E) Distribution of CXCL8 (5.8 (2.7)), (F) Distribution of TNF (7.1 (2.9)), (G) Distribution of IL-6 (2.0 (2.8)), (H) Distribution of Adipsin (682488.6 (247913.1)), (I) Distribution of Adiponectin (8294042.6 (4894863.1)), (J) Distribution of Leptin (8028.4 (7255.1)), (K) Distribution of PAI-1 (12202.2 (3399.8)).

\section{Development of the EDIP scores}

We first calculated the mean daily intake of 17 food groups created from the 24-hour recall questionnaires (Table 1). As seen in previous studies, for model EDIPLimited (EDIP-L), we first applied reduced rank regression (RRR) to derive a dietary 


\section{Columbia Undergraduate Research Journal}

pattern associated with 2 inflammatory biomarkers associated with diseases: IL-6 and TNF-a. (9). Out of the 67 participants, only 23 had data for all biomarkers and were used to build our dietary model. The first factor obtained by RRR, known as the RRR dietary pattern, was used in multivariable regression analysis to identify the most important component food groups. The RRR dietary pattern was used as the dependent variable and the 17 food groups as independent variables with a significance level of $\mathrm{p}<0.05$ for entry into and retention in the model. The intake of the food groups identified in the multivariable regression analyses was weighted by the regression coefficients derived from the final multivariable regression model, and then summed to constitute the EDIP score. Finally, we plotted the biomarkers against the EDIP scores. For our second model, EDIP-All Inclusive (EDIP-AI), all steps were repeated using the same 17 food groups and all 11 biomarkers. Here the EDIP-AI model was calculated using 13 participants.

We then reorganized the food items from the 24-hour recall questionnaires into 14 food groups, and repeated the modeling as described above. For model EDIPLimited New (EDIP-LN), similar to EDIP-L, 23 participants were used to develop the model with IL-6 and TNF-a with the new 14 food groups. For our last model, EDIP-All New (EDIP-AN), all steps were repeated using the same 14 food groups and all 11 biomarkers from 13 participants, similar to EDIP-AI.

\section{Statistical analysis}

The reduced rank regression (RRR) was calculated using the ' $r r r$ ' package in $\mathrm{R}$ (Version 3.6.2). For the empirical development of the four EDIP scores, the relationship between the food groups and the dietary pattern scores was modeled using a multivariable regression analysis. A significance level of $\mathrm{p}<0.05$ was used for retention in the final model. For all models, simple linear regression models were used to see the changes in plasma inflammatory biomarker concentrations across the EDIP scores. P values were reported for linear regression. Later, distribution of the variables across the samples was tested using histograms. All statistical analyses were done using appropriate functions in JMP (SAS) Pro v. 15. P $<0.05$ was considered to indicate statistically significant results.

\section{Results}

Among the 17 food groups entered in the RRR model and the multivariable regression analyses, the components of EDIP-L were not significant, as no food group was determined as a significant contributor to the EDIP. However, after the inclusion of all biomarkers in the analysis, the components of EDIP-AI were: "fruit juice" ( $p=$ $0.0009)$, “snacks" ( $p=0.0008)$, "leafy green vegetables" $(p=0.0074)$, "low-energy beverages" ( $p=0.0098)$, "red meat" $(p=0.0038)$, "fruit" $(p=0.0002)$, and "whole 
wheat grains" ( $p=0.0138)$ as shown in Table 3. The intake of fruit juice, leafy green vegetables, low-energy beverages, red meat, and whole wheat grains was negatively related to concentrations of inflammatory biomarkers (anti-inflammatory), while the intake of snacks and fruit was positively related to concentrations of inflammatory biomarkers (pro-inflammatory).

Table 3: Final components of EDIP-AI with the original 17 food groups and all 11 biomarkers.

\begin{tabular}{|c|c|c|c|c|c|}
\hline $\begin{array}{c}\text { Group } \\
\#\end{array}$ & $\begin{array}{l}\text { Food } \\
\text { Groups }\end{array}$ & Food Items & $\begin{array}{l}\text { Mean } \\
\text { Intakes }\end{array}$ & P value $^{1}$ & Weights $^{2}$ \\
\hline 1 & Fruit juice & $\begin{array}{l}100 \% \text { juice drink } \\
\text { like orange juice, } \\
\text { apple juice, or grape } \\
\text { juice }\end{array}$ & 0.403 & 0.0009 & -0.161379 \\
\hline 2 & Snacks & $\begin{array}{l}\text { Potato chips, tortilla } \\
\text { chips, Cheetos, } \\
\text { corn chips, or other } \\
\text { snack chips }\end{array}$ & 0.627 & 0.0008 & 0.1934998 \\
\hline 3 & $\begin{array}{l}\text { Leafy } \\
\text { green } \\
\text { vegetables }\end{array}$ & $\begin{array}{l}\text { Lettuce, any green } \\
\text { vegetables like } \\
\text { spinach, green } \\
\text { beans, broccoli, } \\
\text { other greens }\end{array}$ & 0.716 & 0.0074 & -0.124367 \\
\hline 4 & $\begin{array}{l}\text { Low- } \\
\text { energy } \\
\text { beverages }\end{array}$ & $\begin{array}{l}\text { Diet sodas or soft } \\
\text { drinks }\end{array}$ & 0.313 & 0.0098 & -0.07809 \\
\hline 5 & Red meat & $\begin{array}{l}\text { Hamburger, hot } \\
\text { dogs, chorizo, steak, } \\
\text { bacon, ribs }\end{array}$ & 0.552 & 0.0038 & -0.121147 \\
\hline 6 & Fruit & $\begin{array}{l}\text { Fruits are all fresh, } \\
\text { frozen, canned or } \\
\text { dried fruits }\end{array}$ & 1.239 & 0.0002 & 0.2621347 \\
\hline 7 & $\begin{array}{l}\text { Whole } \\
\text { Wheat } \\
\text { Grains }\end{array}$ & $\begin{array}{l}\text { Dark bread, buns, } \\
\text { bagels, tortillas, or } \\
\text { rolls or corn tortillas }\end{array}$ & 0.463 & 0.0138 & -0.078844 \\
\hline 8 & Fruit juice & $\begin{array}{l}100 \% \text { juice drink } \\
\text { like orange juice, } \\
\text { apple juice, or grape } \\
\text { juice }\end{array}$ & 0.403 & 0.0009 & -0.161379 \\
\hline 9 & Snacks & $\begin{array}{l}\text { Potato chips, tortilla } \\
\text { chips, Cheetos, }\end{array}$ & 0.627 & 0.0008 & 0.1934998 \\
\hline
\end{tabular}




\section{Columbia Undergraduate Research Journal}

\begin{tabular}{|c|c|c|c|c|c|}
\hline & & $\begin{array}{l}\text { corn chips, or other } \\
\text { snack chips }\end{array}$ & & & \\
\hline 10 & $\begin{array}{l}\text { Leafy } \\
\text { green } \\
\text { vegetables }\end{array}$ & $\begin{array}{l}\text { Lettuce, any green } \\
\text { vegetables like } \\
\text { spinach, green } \\
\text { beans, broccoli, } \\
\text { other greens }\end{array}$ & 0.716 & 0.0074 & -0.124367 \\
\hline 11 & $\begin{array}{l}\text { Low- } \\
\text { energy } \\
\text { beverages }\end{array}$ & $\begin{array}{l}\text { Diet sodas or soft } \\
\text { drinks }\end{array}$ & 0.313 & 0.0098 & -0.07809 \\
\hline 12 & Red meat & $\begin{array}{l}\text { Hamburger, hot } \\
\text { dogs, chorizo, steak, } \\
\text { bacon, ribs }\end{array}$ & 0.552 & 0.0038 & -0.121147 \\
\hline 13 & Fruit & $\begin{array}{l}\text { Fruits are all fresh, } \\
\text { frozen, canned or } \\
\text { dried fruits }\end{array}$ & 1.239 & 0.0002 & 0.2621347 \\
\hline
\end{tabular}

${ }^{1} \mathrm{p}$ values are reported from multivariable regression, $\mathrm{p}<0.05$.

${ }^{2}$ Values are regression coefficients for each EDIP-AI food component obtained from the last step of the multivariable regression analysis.

The distribution of the EDIP-AI scores suggests the majority of participants had a pro-inflammatory diet, likely driven by increased consumption of snacks and fruits. After calculating the EDIP scores for each participant, we plotted all the biomarkers against the EDIP scores. TNF-a $(p=0.0018)$, IL-6 ( $p=0.0105)$, CCL19 $(p=0.0210), \operatorname{CCL} 2(p=0.0091), \operatorname{CXCL} 9(p=0.0220)$, and Leptin $(p=0.0100)$ all show significant positive correlations with EDIP scores as seen in Figure 2.

When assessing adiponectin, an anti-inflammatory biomarker, against EDIP scores, we expected to see an inverse correlation (Figure 2G). However, adiponectin behaved differently than anticipated and showed a non-significant positive association with the EDIP scores. We hypothesize that BMI could be one of the factors that influenced the association, but it is not definitive. 

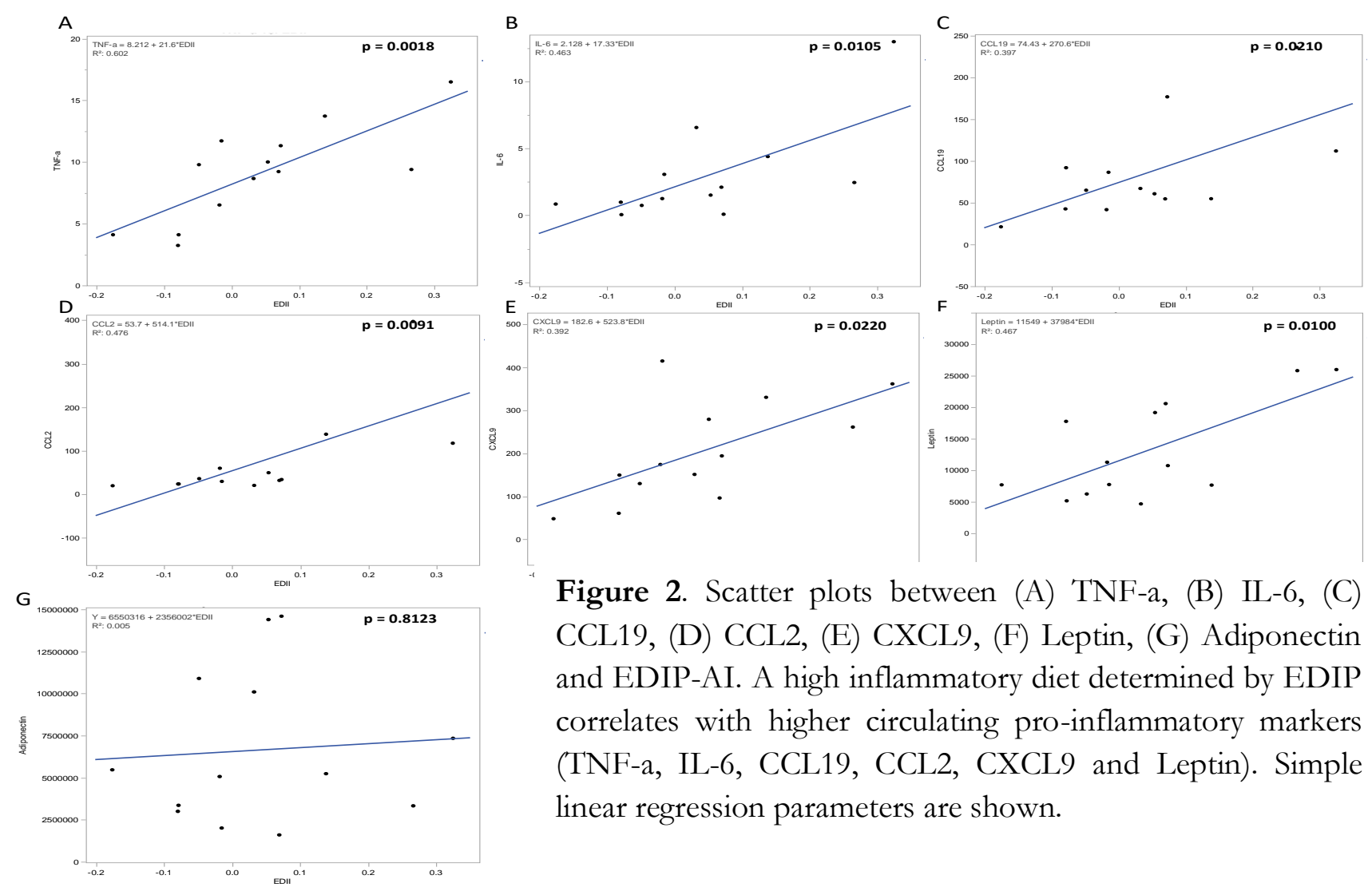

Figure 2. Scatter plots between (A) TNF-a, (B) IL-6, (C) CCL19, (D) CCL2, (E) CXCL9, (F) Leptin, (G) Adiponectin and EDIP-AI. A high inflammatory diet determined by EDIP correlates with higher circulating pro-inflammatory markers (TNF-a, IL-6, CCL19, CCL2, CXCL9 and Leptin). Simple linear regression parameters are shown.

Similarly, among the 14 food groups entered in the RRR model and the multivariable regression analyses, the components of EDIP-LN were not significantno food group was assessed as a significant contributor to the EDIP. However, the components of EDIP-AN were: "fruit juice" ( $p=0.0107)$, "snacks" ( $p=0.0116)$, and "fruit" ( $p=0.0026)$, shown in Table 4. The intake of fruit juice was inversely related to concentrations of inflammatory biomarkers, while the intake of snacks and fruit was positively related to concentrations of inflammatory markers; these results are similar to the earlier model, EDIP-AI.

Table 4: Final components of EDIP-AN with the revised 14 food groups and all 11 biomarkers.

\begin{tabular}{|c|l|l|l|l|l|}
\hline $\begin{array}{c}\text { Group } \\
\#\end{array}$ & $\begin{array}{l}\text { Food } \\
\text { Groups }\end{array}$ & Food Items & $\begin{array}{l}\text { Mean } \\
\text { Intakes }\end{array}$ & P value $^{1}$ & Weights $^{2}$ \\
\hline $\mathbf{1}$ & $\begin{array}{l}\text { Fruit } \\
\text { juice }\end{array}$ & $\begin{array}{l}100 \% \text { juice drink } \\
\text { like orange juice, } \\
\text { apple juice, or } \\
\text { grape juice }\end{array}$ & 0.403 & 0.0107 & -0.504049 \\
\hline 2 & Snacks & $\begin{array}{l}\text { Potato chips, } \\
\text { tortilla chips, }\end{array}$ & 0.627 & 0.0116 & 0.6905991 \\
\hline
\end{tabular}




\begin{tabular}{|l|l|l|l|l|l|}
\hline & & $\begin{array}{l}\text { Cheetos, corn } \\
\text { chips, or other } \\
\text { snack chips }\end{array}$ & & & \\
\hline 10 & Fruit & $\begin{array}{l}\text { Fruits are all fresh, } \\
\text { frozen, canned or } \\
\text { dried fruits }\end{array}$ & 0.0026 & 0.7423546 \\
\hline
\end{tabular}

${ }^{1} \mathrm{p}$ values are reported from multivariable regression, $\mathrm{p}<0.05$.

${ }^{2}$ Values are regression coefficients for each EDIP-AN food component obtained from the last step of the multivariable regression analysis.

The distribution of EDIP-AN suggests all the participants had a proinflammatory diet, therefore consumed more snacks and fruits. After plotting the biomarkers against the EDIP scores, CXCL9 ( $p=0.0091)$, TNF-a $(p=0.0292)$ and Leptin ( $p=0.0207$ ) all show significant positive correlations with EDIP scores (Figure 3). Like before, when plotting adiponectin against EDIP scores, we expected to see an inverse correlation. However, adiponectin showed a positive association with the EDIP scores, which could be due to BMI, but it is not definitive (Figure 3D).
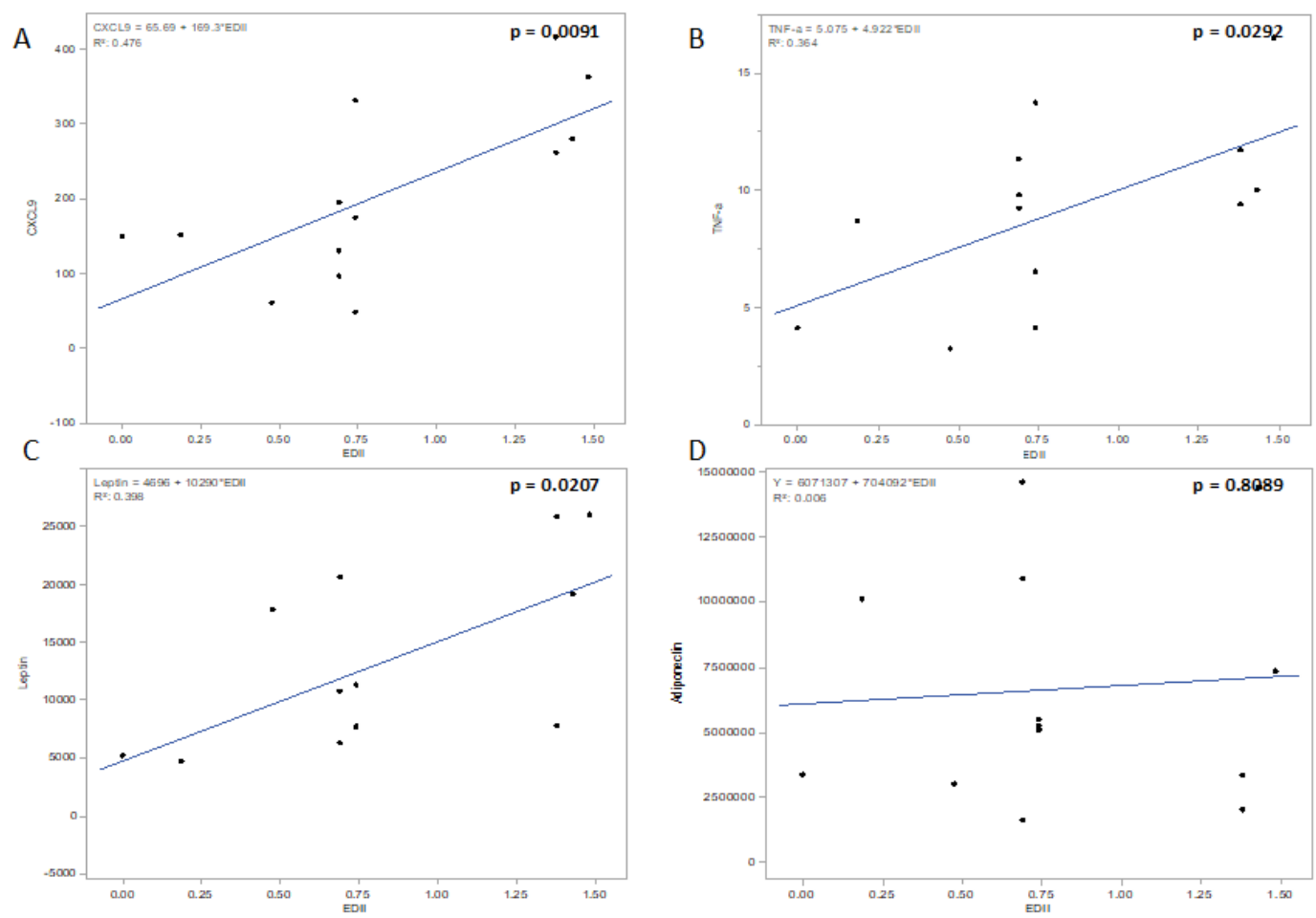

Figure 3: Scatter plots between (A) CXCL9, (B) TNF-a, (C) Leptin, (D) Adiponectin and EDIP-AN. A high inflammatory diet determined by EDIP correlates with higher circulating pro-inflammatory markers (CXCL9, TNF-a, Leptin). Simple linear regression parameters are shown. 
Among the 13 participants included in EDIP-AI and EDIP-AN, the majority were Caucasian/white and used aspirin or NSAID drugs regularly, as shown in Table 5. The average BMI was 31.50, and the majority of our participants were overweight or obese. Lastly, $69.23 \%$ of the participants had at least one chronic condition, including diabetes and high blood pressure.

Table 5: Characteristics of participants included in EDIP-AI and EDIP-AN.

\begin{tabular}{|l|r|}
\hline Characteristics & $\begin{array}{c}\text { Participants } \\
\text { (n= 13) }\end{array}$ \\
\hline Age at time of survey & $44.77 \pm 16.53^{\mathrm{a}}$ \\
\hline Ethnicity (\%) & 15.38 \\
\hline African American & 7.69 \\
\hline Asian American & 76.92 \\
\hline Caucasian/white & $31.50 \pm 6.54$ \\
\hline BMI & 23.08 \\
\hline BMI Categorized (\%) & 23.08 \\
\hline $18.5 \leq 25$ & 53.85 \\
\hline $25 \leq 30$ & 38.46 \\
\hline$>30$ & 15.38 \\
\hline Smoking (\%) & 61.54 \\
\hline Alcohol (\%) & \\
\hline Oral Contraceptives (\%) & 53.84 \\
\hline Menopausal Status (\%) & 46.15 \\
\hline Premenopause & 76.92 \\
\hline Postmenopause & \\
\hline Regular aspirin/NSAID & \\
\hline users (\%) & \\
\hline Chronic conditions (\%) & \\
\hline 0 & 30.77 \\
\hline 1 & 15.38 \\
\hline 2 & 23.08 \\
\hline$\geq 3$ & 30.77 \\
\hline
\end{tabular}

${ }^{\mathrm{a}}$ All such values are mean $\pm \mathrm{SD}$

${ }^{\mathrm{b}}$ All alcohol consumption in the last 30 days before survey completion

${ }^{\mathrm{c}}$ Chronic conditions included were high cholesterol, cancer, diabetes, high blood pressure, heart disease, rheumatoid arthritis and multiple sclerosis

\section{Discussion}

Findings demonstrate the EDIP scores differ based on the inflammatory biomarkers and food groups used in the analysis on the same noncancer controls. Depending on the methods used, an individual's diet may be considered more pro- or anti-inflammatory. Even though EDIP-AI and EDIP-AN were developed using 


\section{Columbia Undergraduate Research Journal}

different food groups, the majority of people seemed to have a pro-inflammatory diet and a higher consumption of fruits and snacks. Surprisingly, key components of the Standard American Diet (SAD), such as processed meat, dairy products and refined grains, were not significant in any of the models, suggesting these were not the most important component food groups contributing to the RRR dietary pattern in our sample.

Interestingly, when deriving the EDIP scores with IL-6 and TNF-a only with either 14 or 17 food groups, there were no significant component food groups. We started by looking at IL-6 and TNF-a only since these inflammatory markers have already been associated with a number of diseases, such as colorectal cancer, coronary disease and depression, and are among the most commonly used inflammatory markers to examine disease endpoints (9). However, once all biomarkers were included in the analysis, we were able to derive an EDIP score. The number and type of inflammatory biomarkers seem to influence the components of EDIP scores, at least in our sample. The factors explaining the observed differences in EDIP models are not clear.

The food groups were first organized based on Tabung et al.'s study (9). However, there were discrepancies between our 24-hour recall questionnaire and their study's food groups (9). For example, our questionnaire asked how many times our participants consumed hamburgers, hot dogs, chorizo, steak, bacon, and ribs in one question. In EDIP-AI, this was grouped under Red meat, but some food items in the list are considered processed meat. As a result, in EDIP-AN, we combined food groups Red meat and Processed meat into Meat to try to improve the accuracy of our food groups. Interestingly, the three components of EDIP-AN were also found in EDIP-AI, with the same correlations but slightly different weight numbers. Even though food items were reorganized, the significant food groups maintained the same trends. However, some food groups did lose their significance when we reorganized the food items. For example, in EDIP-AI, red meat and whole wheat grains were significant components, but after combining red meat with processed meat into the food group meat and whole grains with refined grains into the food group grains, these groups lost their significance.

In our study, fruit juice has a negative weight, and is therefore considered antiinflammatory. Some fruit juices can have more anti-inflammatory properties than others, however in our study, we combined data for orange, apple and grape juice as one food category. Studies have shown that orange juice could prevent and treat chronic diseases by mediating the inflammatory response level and gene expression (17). For example, orange juice was able to mitigate the increase of inflammation induced by a meal composed of high saturated fat (17). Surprisingly, in model EDIP$\mathrm{AI}$, red meat was negatively related to concentrations of inflammatory markers, suggesting it is anti-inflammatory. In the original study by Tabung et al. (9), red meat was positively associated with inflammatory markers in the US population. Other

VOL $5 \mid 14$ 


\section{Columbia Undergraduate Research Journal}

studies also suggest that higher red meat consumption is significantly associated with higher C-reactive protein (CRP), a pro-inflammatory biomarker related to chronic diseases (18). However, the Multiethnic Cohort Study found that BMI mediated the association between red meat and plasma inflammatory biomarkers. Lastly, in both models, fruit is pro-inflammatory. Some studies have shown that fruits contain high levels of phytochemicals that have an anti-inflammatory effect by downregulating the transcription of pro-inflammatory biomarkers (19). A high intake of fruits and vegetables protects against heart diseases, cognitive impairment and some types of cancers (20). These associations could be due to confounding factors, such as BMI and the use of supplements, but these have not been further studied.

Interestingly, in our study, the majority of our participants were overweight or obese and had at least one chronic condition linked to inflammation, such as diabetes and rheumatoid arthritis. Obesity, the accumulation of abnormal fat, has been associated with increased inflammation (21). The excess fat stimulates the release of inflammatory biomarkers, such as TNF-a, IL-6 and CRP, but decreases adiponectin production from adipose tissues, which leads to systemic inflammation in obese patients (21). Systemic inflammation plays an important role in the development of diabetes and metabolic syndrome by promoting insulin resistance (21). This suggests the majority of our participants had underlying inherent inflammation. As a result, some participants could consume an anti-inflammatory diet, but still have high levels of inflammation, therefore skewing our data.

This study does have limitations. We only had data from 24-hour recalls, but this empirical dietary inflammatory index was developed and validated using food frequency questionnaires. The 24-hour recall method also has measurement errors, due to misreporting of nutritional data by participants and memory bias. The questions in our questionnaire were also very broad, each question asked about multiple food items, making it difficult to organize our data into food groups and analyze the separate effects of each food item on inflammation. Since some items that were grouped together had different pro- or anti-inflammatory effects, this could explain why some key components of SAD were not significant in our models. We also had a very small sample size, which could have reduced the power of our study and increased the margin of error. A larger sample size could improve detection of associations between food groups and the 11 plasma inflammatory biomarkers. We also did not take into account any confounding factors, which could have significantly affected our trends, especially for adiponectin.

Overall, this study provides insight into the inflammatory potential of an individual's diet and the factors that may affect how we calculate this potential. Even though this was done using 24-hour recalls and noncancer women controls, it is our goal to apply these methods on food frequency questionnaire data obtained from African women with TNBC. We have developed a new food frequency questionnaire inspired by the NHS' questionnaire, the food groups from Tabung et al.'s study (9),

VOL $5 \mid 15$ 


\section{Columbia Undergraduate Research Journal}

and specific ethnic food items from Ghana, Nigeria and Ethiopia. Our questionnaire has 29 food groups and 109 food items. We will start collecting data to hopefully study the effects of dietary patterns on inflammation in breast cancer patients, focusing on Duffy-Null women who typically have higher levels of plasma inflammatory chemokines.

\section{WORKS CITED}

Rachel Martini, et al., In vivo characterization of the Duffy Antigen Receptor for Chemokines (DARC) in the breast cancer microenvironment [abstract]. In: Proceedings of the American Association for Cancer Research Annual Meeting 2018; 2018 Apr 14-18; Chicago, IL. Philadelphia (PA): AACR; Cancer Res 2018;78(13 Suppl):Abstract nr 5119.

Hansell CA, Hurson CE, Nibbs RJ. DARC and D6: silent partners in chemokine regulation? Immunol Cell Biol. 2011;89:197-206.

Howes RE, et al. The global distribution of the Duffy blood group. Nat Commun. 2011;2:266.

Newman LA, Jenkins B, Chen Y, et al. Hereditary Susceptibility for Triple Negative Breast Cancer Associated With Western Sub-Saharan African Ancestry: Results From an International Surgical Breast Cancer Collaborative. Ann Surg. 2019;270(3):484-492.

Jenkins $\mathrm{BD}$, Martini RN, Hire $\mathrm{R}$, et al. Atypical Chemokine Receptor 1 (DARC/ACKR1) in Breast Tumors Is Associated with Survival, Circulating Chemokines, Tumor-Infiltrating Immune Cells, and African Ancestry. Cancer Epidemiol Biomarkers Prev. 2019;28(4):690-700.

Dawood S, Lei X, Dent R, et al. Survival of women with inflammatory breast cancer: a large population-based study. Ann Oncol. 2014;25(6):1143-1151.

Hu FB. Dietary pattern analysis: A new direction in nutritional epidemiology. Curr Opin Lipidol. 2002.

Oude Griep LM, Wang H, Chan Q. Empirically Derived Dietary Patterns, Diet Quality Scores, and Markers of Inflammation and Endothelial Dysfunction. Curr Nutr Rep. 2013.

Tabung FK, Smith-Warner SA, Chavarro JE, et al. Development and Validation of an Empirical Dietary Inflammatory Index. J Nutr. 2016;146(8):1560-1570.

Hoffmann K, Schulze MB, Schienkiewitz A, No thlings U, Boeing H. Application of a new statistical method to derive dietary patterns in nutritional epidemiology. Am J Epidemiol. 2004;159:935-44.

Hoffmann K, Zyriax BC, Boeing H, Windler E. A dietary pattern derived to explain biomarker variation is strongly associated with the risk of coronary artery disease. Am J Clin Nutr. 2004;80:633-40. 


\section{Columbia Undergraduate Research Journal}

Jankovic N, Steppel MT, Kampman E, de Groot LC, Boshuizen HC, SoedamahMuthu SS, Kromhout D, Feskens EJ. Stability of dietary patterns assessed with reduced rank regression; the Zutphen Elderly Study. Nutr J. 2014;13:30.

Krintus M, Kozinski M, Kubica J, Sypniewska G. Critical appraisal of inflammatory markers in cardiovascular risk stratification. Crit Rev Clin Lab Sci. 2014;51:263-79.

Donath MY, Shoelson SE. Type 2 diabetes as an inflammatory disease. Nat Rev Immunol. 2011;11:98-107.

Guina T, Biasi F, Calfapietra S, Nano M, Poli G. Inflammatory and redox reactions in colorectal carcinogenesis. Ann NY Acad Sci. 2015;1340:95-103.

Jenkins BD, Martini RN, Hire R, et al. Atypical Chemokine Receptor 1 (DARC/ACKR1) in Breast Tumors Is Associated with Survival, Circulating Chemokines, Tumor-Infiltrating Immune Cells, and African Ancestry. Cancer Epidemiol Biomarkers Prev. 2019;28(4):690-700.

Rocha DMUP, Lopes LL, da Silva A, Oliveira LL, Bressan J, Hermsdorff HHM. Orange juice modulates proinflammatory cytokines after high-fat saturated meal consumption. Food Funct. 2017;8(12):4396-4403.

Chai W, Morimoto Y, Cooney RV, et al. Dietary Red and Processed Meat Intake and Markers of Adiposity and Inflammation: The Multiethnic Cohort Study. J Am Coll Nutr. 2017;36(5):378-385.

Fengmei Zhu, Bin Du \& Baojun Xu. Anti-inflammatory effects of phytochemicals from fruits, vegetables, and food legumes: A review. Critical Reviews in Food Science and Nutrition. 2018;58(8):1260-1270.

Wallace TC, Bailey RL, Blumberg JB, Burton-Freeman B, Chen CO, Crowe-White KM, et al. Fruits, vegetables, and health: A comprehensive narrative, umbrella review of the science and recommendations for enhanced public policy to improve intake. Crit Rev Food Sci Nutr. 2019.

Ellulu, Mohammed S., et al. Obesity and Inflammation: the Linking Mechanism and the Complications. Archives of Medical Science, 2017;4:851-863. 